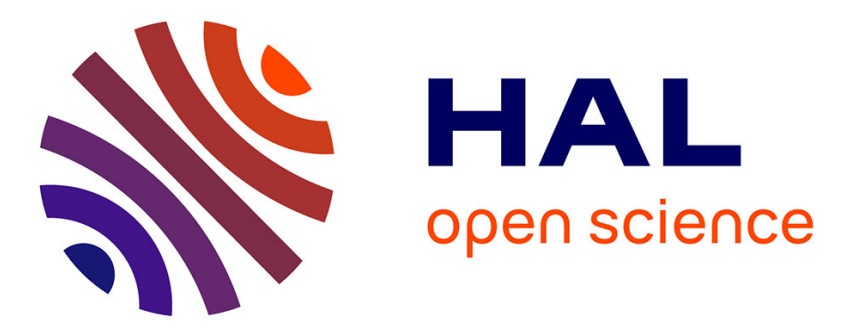

\title{
Genuine open form of the pentameric ligand-gated ion channel GLIC
}

\author{
Zaineb Fourati, Ludovic Sauguet, Marc Delarue
}

\section{To cite this version:}

Zaineb Fourati, Ludovic Sauguet, Marc Delarue. Genuine open form of the pentameric ligand-gated ion channel GLIC. Acta crystallographica Section D : Structural biology [1993-..], 2015, 71 (3), pp.454460. $10.1107 /$ S1399004714026698 . pasteur-02174633

\section{HAL Id: pasteur-02174633}

\section{https://hal-pasteur.archives-ouvertes.fr/pasteur-02174633}

Submitted on 5 Jul 2019

HAL is a multi-disciplinary open access archive for the deposit and dissemination of scientific research documents, whether they are published or not. The documents may come from teaching and research institutions in France or abroad, or from public or private research centers.
L'archive ouverte pluridisciplinaire HAL, est destinée au dépôt et à la diffusion de documents scientifiques de niveau recherche, publiés ou non, émanant des établissements d'enseignement et de recherche français ou étrangers, des laboratoires publics ou privés.

\section{(1) (1) $\$$}

Distributed under a Creative Commons Attribution - NonCommercial - NoDerivatives $\mid 4.0$ 
BIOLOGICAL CRYSTALLOGRAPHY

ISSN 1399-0047

Received 24 July 2014

Accepted 4 December 2014

Keywords: GLIC; ligand-gated ion channel.

PDB references: GLIC, 4qh5; complex with bromoacetate, $4 \mathrm{qh} 1$

Supporting information: this article has supporting information at journals.iucr.org/d

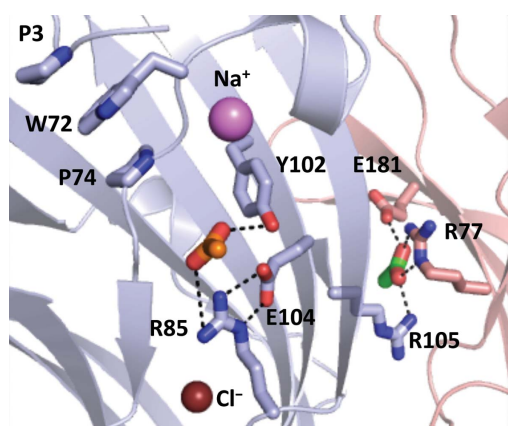

C 2015 International Union of Crystallography

\section{Genuine open form of the pentameric ligand-gated ion channel GLIC}

\author{
Zaineb Fourati, Ludovic Sauguet and Marc Delarue*
}

Unit of Structural Dynamics of Macromolecules, Institut Pasteur and UMR 3528 du CNRS, 25 Rue du Docteur Roux, 75015 Paris, France. *Correspondence e-mail: delarue@pasteur.fr

Pentameric ligand-gated ion channels (pLGICs) mediate fast chemical neurotransmission of nerve signalling in the central and peripheral nervous systems. GLIC is a bacterial homologue of eukaryotic pLGIC, the X-ray structure of which has been determined in three different conformations. GLIC is thus widely used as a model to study the activation and the allosteric transition of this family of receptors. The recently solved high-resolution structure of GLIC (2.4 $\AA$ resolution) in the active state revealed two bound acetate molecules in the extracellular domain (ECD). Here, it is shown that these two acetates exactly overlap with known sites of pharmacological importance in pLGICs, and their potential influence on the structure of the open state is studied in detail. Firstly, experimental evidence is presented for the correct assignment of these acetate molecules by using the anomalous dispersion signal of bromoacetate. Secondly, the crystal structure of GLIC in the absence of acetate was solved and it is shown that acetate binding induces local conformational changes that occur in strategic sites of the ECD. It is expected that this acetate-free structure will be useful in future computational studies of the gating transition in GLIC and other pLGICs.

\section{Introduction}

Pentameric ligand-gated ion channels (pLGICs) are found in organisms ranging from prokaryotes to humans. In vertebrates, these receptors mediate fast neurotransmission in the central and peripheral nervous systems and include the nicotinic acetylcholine receptor (nAChR), serotonin receptor $\left(5 \mathrm{HT}_{3}\right)$, glycine receptor (GlyR) and $\gamma$-aminobutyric acid type A receptor $\left(\mathrm{GABA}_{\mathrm{A}}-\mathrm{R}\right)$. Upon agonist binding in the extracellular domain (ECD) at the interface between subunits, the pore opens up, allowing ion permeation and therefore chemoelectric signal transduction. Structural studies of pLGICs from Gloeobacter violaceus (GLIC) and Erwinia chrysanthemi (ELIC) as well as the eukaryotic $\mathrm{GluCl}$ receptor from Caenorhabditis elegans and, more recently, the human $\mathrm{GABA}_{\mathrm{A}}$ receptor (Miller \& Aricescu, 2014) and the mouse 5-HT3 receptor (Hassaine et al., 2014) have provided insights into the activation and modulation of this family of receptors (for a review, see Corringer et al., 2012). GLIC presents the most comprehensive system to date to study the structural transitions that occur during activation as its structure has been solved in the active state (Bocquet et al., 2009; Sauguet, Poitevin et al., 2013), in a locally closed conformation (Prevost et al., 2012) and recently in the resting state (Sauguet, Shahsavar, Poitevin et al., 2014). Moreover, GLIC structures in complex with ethanol and general anaesthetics allowed the unravelling of several molecular determinants of pLGIC 

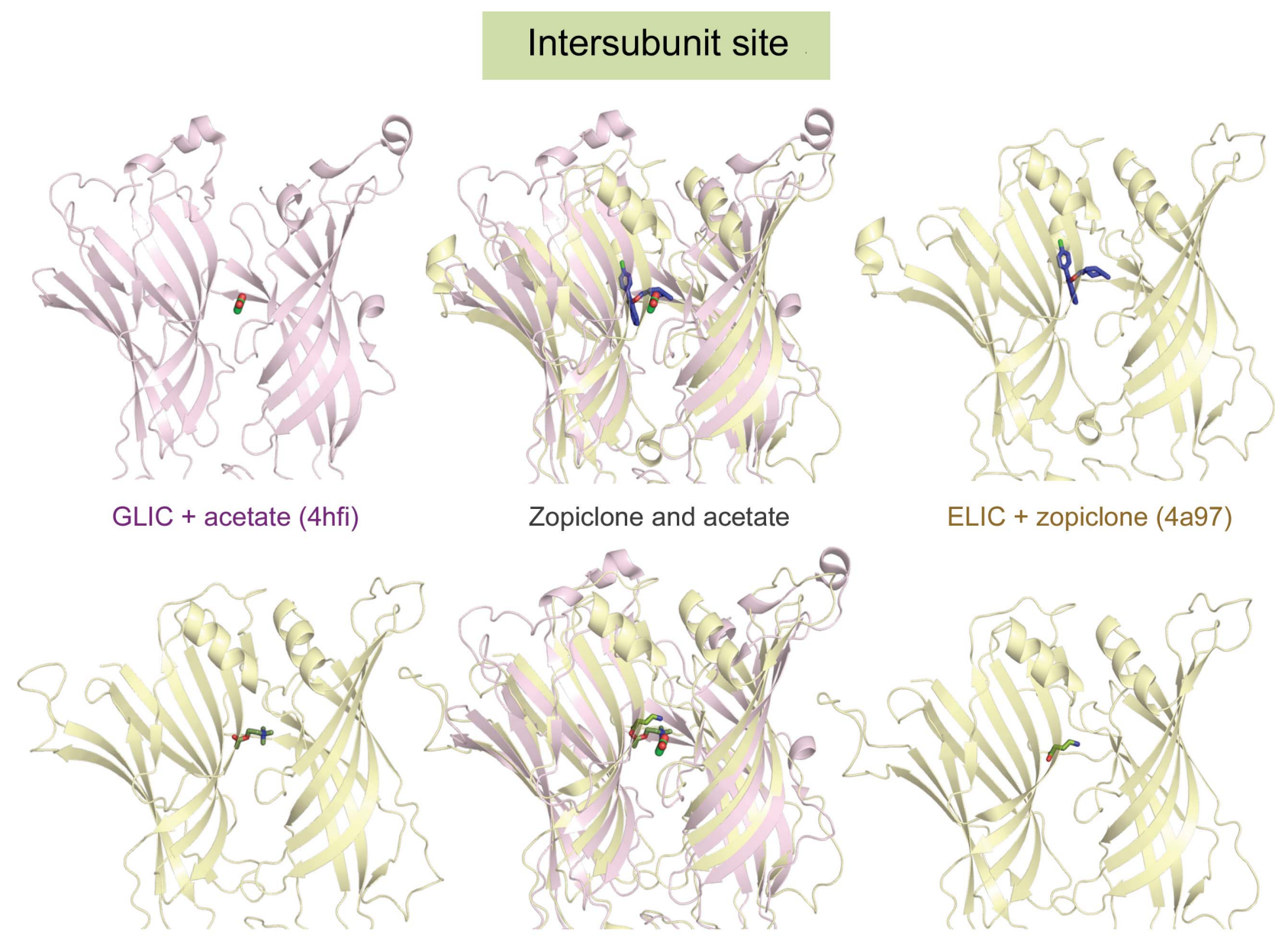

ELIC + acetylcholine
$(3 r q w)$

Zopiclone and acetate

ELIC + zopiclone (4a97)
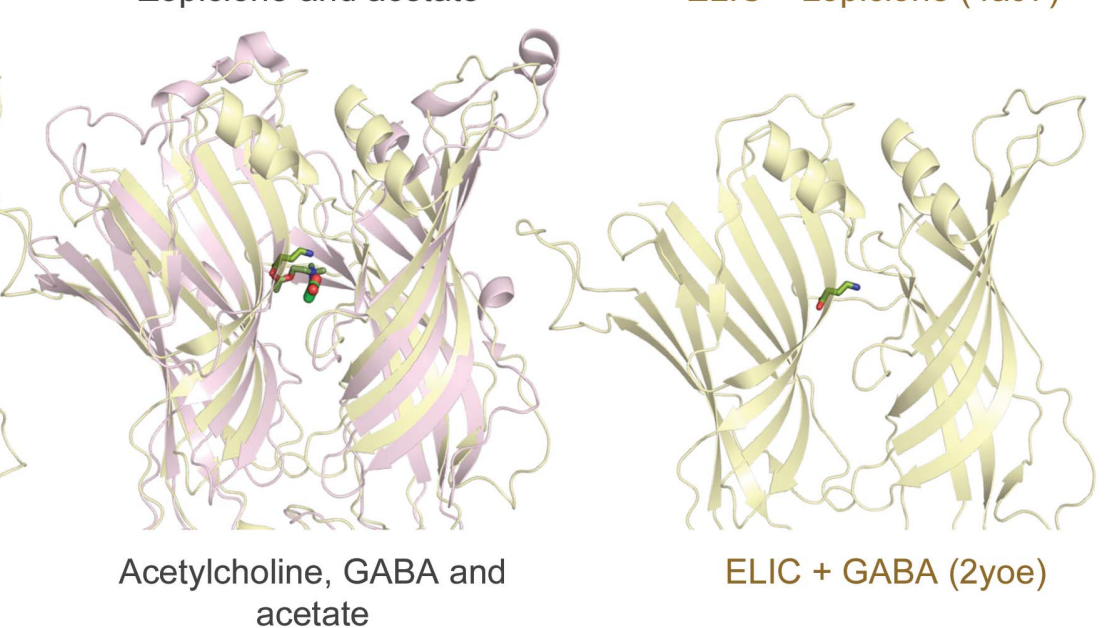

$(a)$

\section{Intrasubunit site}

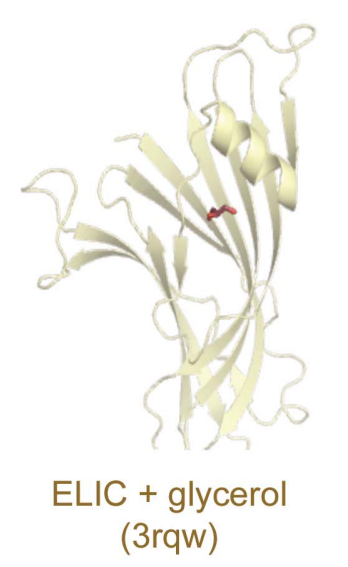

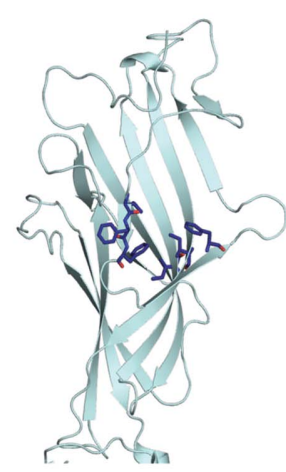

GlyR a1: model of

$\mathrm{Zn}^{2+}$ inhibition site

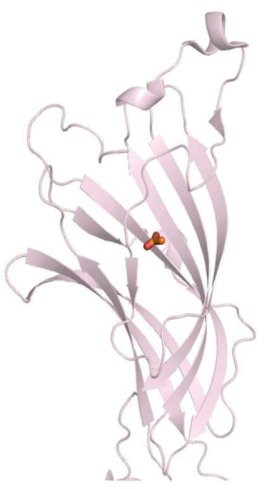

GLIC + acetate

(4hfi)

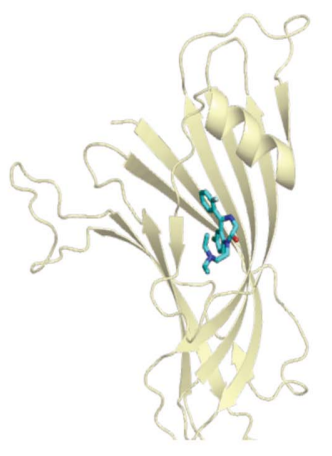

ELIC + flurazepam

(2yoe)

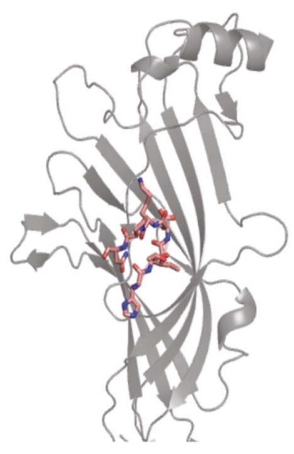

GluCl (insertion)

(3rif)

(b)

Figure 1

(a) Intersubunit site. Acetate-binding sites overlap with known pLGIC modulation/orthosteric sites. Intersubunit site. Upper panel: ELIC with bound benzodiazepine zopiclone (right), GLIC with bound intersubunit acetate (left) and ELIC and GLIC superimposed with bound zopiclone and acetate, respectively (centre). Lower panel: ELIC with bound acetylcholine (left), ELIC with bound GABA (right) and ELIC and GLIC superimposed with bound acetylcholine, GABA and acetate (centre). (b) Intrasubunit site. From left to right: ELIC with glycerol, GlyR $\alpha 1$ model of zinc-mediated inhibition (Miller et al., 2008), GLIC with bound chloride ion and intrasubunit acetate, ELIC with benzodiazepine flurazepam and GluCl with the pre- $\beta 5$ loop from the neighbouring subunit occupying the intrasubunit site. The same insertion is also seen in GABA-R (4cof). 
Table 1

Data-collection and refinement statistics.

Values in parentheses are for the highest resolution shell.

\begin{tabular}{|c|c|c|}
\hline & GLIC-phosphate & GLIC-bromoacetate \\
\hline \multicolumn{3}{|l|}{ Data collection } \\
\hline Space group & $C 2$ & $C 2$ \\
\hline $\begin{array}{l}\text { Unit-cell parameters } \\
\left(\AA,{ }^{\circ}\right)\end{array}$ & $\begin{array}{c}a=181.9, b=134.4 \\
\quad c=160.0, \beta=102.7\end{array}$ & $\begin{array}{c}a=181.4, b=134.0 \\
\quad c=158.8, \beta=101.0\end{array}$ \\
\hline Resolution $(\AA)$ & $49.93-2.80(2.95-2.80)$ & $49.40-3.39(3.57-3.39)$ \\
\hline$R_{\text {p.i.m. }}$ & $0.041(0.846)$ & $0.057(0.454)$ \\
\hline$R_{\text {merge }}$ & $0.060(1.253)$ & $0.115(0.910)$ \\
\hline $\mathrm{CC}_{1 / 2}$ & $0.99(0.880)$ & $0.99(0.664)$ \\
\hline$\langle I / \sigma(I)\rangle$ & $11.2(1.2)$ & $9.6(1.8)$ \\
\hline Completeness (\%) & $96.1(96.7)$ & $99.5(97.6)$ \\
\hline Multiplicity & $3.0(3.0)$ & $5.9(5.9)$ \\
\hline \multicolumn{3}{|l|}{ Refinement } \\
\hline Resolution $(\AA)$ & $20-3.0$ & $20-3.4$ \\
\hline No. of reflections & 71851 & 51007 \\
\hline$R$ factor $/ R_{\text {free }}(\%)$ & $19.9 / 21.6$ & $20.2 / 22.5$ \\
\hline \multicolumn{3}{|l|}{ No. of atoms } \\
\hline Protein & 12625 & 12634 \\
\hline Ligand/ion & 205 & 95 \\
\hline \multicolumn{3}{|l|}{$B$ factors $\left(\AA^{2}\right)$} \\
\hline Protein & 108.75 & 119.55 \\
\hline Ligand/ion & 100.68 & 99.5 \\
\hline \multicolumn{3}{|l|}{ Ramachandran plot } \\
\hline Favoured (\%) & 96 & 98.3 \\
\hline Outliers (\%) & 0.06 & 0 \\
\hline MolProbity score $\dagger$ & 100th percentile & 100th percentile \\
\hline \multicolumn{3}{|l|}{ R.m.s. deviations } \\
\hline Bond lengths $(\AA)$ & 0.01 & 0.01 \\
\hline Bond angles $\left({ }^{\circ}\right)$ & 1.07 & 1.01 \\
\hline
\end{tabular}

$\dagger$ The 100th percentile is the best among structures of comparable resolution; the 0th is the worst.

allosteric modulation (Nury et al., 2011; Sauguet, Howard et al. 2013). Indeed, Cys-loop receptors (pLGICs) are modulated by a wide range of molecules, including alcohols, ivermectin, metal ions, benzodiazepines and general anaesthetics (GAs) (Miller \& Smart, 2010; Corringer et al., 2012). Alcohols and GAs usually bind at well conserved cavities (either intrasubunit or intersubunit cavities) in the transmembrane domain (Sauguet, Howard et al., 2013), except for bromoform, which displays an additional extracellular binding site in ELIC (Spurny et al., 2013). However, a number of molecules modulate pLGIC upon binding at the extracellular domain. For instance, $\mathrm{Zn}^{2+}$ is an allosteric modulator of some members of the pLGIC family and it modulates the GlyR receptor in a biphasic fashion through two distinct sites on the ECD (Bloomenthal et al., 1994; Laube, 2002; Miller et al., 2008; Fig. 4). In addition, benzodiazepines are also known to exert a biphasic modulation of $\mathrm{GABA}_{\mathrm{A}}$ receptors through bipartite binding at both a nanomolar and a micromolar affinity site on the ECD (Walters et al., 2000). The molecular determinants of benzodiazepine modulation were further investigated in ELIC by X-ray crystallography (Spurny et al., 2012). It was found that they bind with high affinity to a potentiation intrasubunit site facing the vestibule. They also bind to a second intersubunit site that partially overlaps with the orthosteric site and is a low-affinity inhibitory site.

The recently solved high-resolution structure of GLIC in the active (open) state revealed the presence of two acetate molecules (Sauguet, Poitevin et al., 2013). One lies immedi- ately below the putative orthosteric site. The other acetate molecule, which had already been observed in the structure of the ECD alone (Nury et al., 2010), occupies an intrasubunit pocket located $12 \AA$ away from the first acetate site. Strikingly, the first acetate site overlaps with the intersubunit inhibition benzodiazepine site, while the second overlaps with the intrasubunit potentiation benzodiazepine site (Fig. 1). Furthermore, in a recent crystallographic study describing the binding of acetylcholine in the orthosteric site of ELIC (Pan et al., 2012), extra electron density (interpreted as a glycerol molecule) was found very close to the intrasubunit acetatebinding site observed in GLIC (Fig. 1). These findings suggest that the two acetate molecules bind at well conserved cavities that correspond to the modulation sites common to many members of the pLGIC family (Sauguet, Shahsavar \& Delarue, 2014). Moreover, the carboxyl group is present in most known neurotransmitters (GABA, glycine, glutamate etc.). Here, we further investigate the possible role of acetate at the structural level, as we were concerned that acetate binding might modify the conformation of the GLIC active state. In particular, we solved the structure of GLIC with a bromine-substituted derivative of acetate in order to accurately locate the acetate-binding sites in GLIC. We then analyzed the effect of acetate binding itself by solving the GLIC structure in a phosphate buffer at the same $\mathrm{pH}(\mathrm{pH} 4)$.

\section{Materials and methods}

\subsection{Protein production}

GLIC fused to maltose-binding protein was expressed in Escherichia coli $\mathrm{C} 43$ cells and purified as described previously (Sauguet, Poitevin et al., 2013).

\subsection{Crystallography}

2.2.1. Crystal preparation. All crystals were obtained using vapour diffusion in hanging drops at $20^{\circ} \mathrm{C}$.

The concentrated $\left(10 \mathrm{mg} \mathrm{ml}^{-1}\right)$ protein was mixed in a $1: 1$ ratio with reservoir solution typically consisting of $12-14.5 \%$ PEG 4000, $400 \mathrm{~m} M$ sodium thiocyanate, 2\% dimethyl sulfoxide (DMSO), 16\% glycerol, $100 \mathrm{~m} M$ phosphate buffer $\mathrm{pH} 4$ or sodium acetate $\mathrm{pH} 4$. Crystallization was enhanced by the micro-seeding technique from a solution of crushed crystals (grown in the same crystallization condition: $100 \mathrm{~m} M$ sodium acetate $\mathrm{pH}$ 4, $400 \mathrm{mM}$ sodium thiocyanate, $16 \%$ glycerol, $12 \%$ PEG 4000, 2\% DMSO) $1 \mathrm{~h}$ after setting up the crystallization experiment. Crystals appeared overnight with a parallelepipedlike shape and grew for one week before reaching their final dimensions.

Bromoacetate-substituted crystals were obtained by adding $4 \mu \mathrm{l}$ of a solution consisting of $15 \%$ PEG 4000, $400 \mathrm{mM}$ sodium thiocyanate, 2\% DMSO, 16\% glycerol, $100 \mathrm{mM}$ bromoacetate $\mathrm{pH} 4$ to the $1 \mu \mathrm{l}$ crystallization drop containing the fully grown crystals in sodium acetate buffer $\mathrm{pH} 4$. A short soak was allowed to occur for $30 \mathrm{~s}$ to $3 \mathrm{~min}$, after which the crystals were directly flash-cooled in liquid nitrogen. 
2.2.2. Data collection. All of the crystals were directly flash-cooled in liquid nitrogen prior to data collection. Data sets were collected on the PROXIMA1 beamline of the SOLEIL synchrotron, Gif-sur-Yvette, France and on beamline ID23-1 of the European Synchrotron Radiation Facility (ESRF), Grenoble, France. For the bromoacetate-substituted crystals, data sets were collected at the peak wavelength of bromine (0.9191 ^). Reflections were integrated using XDS (Kabsch, 2010) and further processed using programs from the CCP4 suite (Winn et al., 2011). As expected, crystals of GLIC grown at $\mathrm{pH} 4$ were isomorphous to the previously described crystal lattice of the open receptor and belonged to space group $C 121$ (unit-cell parameters $a=113.5, b=127.6$, $c=185.8 \AA, \alpha=\gamma=90, \beta=101^{\circ}$ ) with one pentamer in the asymmetric unit (see Table 1).

2.2.3. Phasing and refinement. The phases were directly calculated by performing rigid-body refinement with REFMAC5 (Murshudov et al., 2011) using PDB entry 3eam (Bocquet et al., 2009) as a starting model. The structure was then subjected to restrained refinement with REFMAC5 using NCS restraints. The resulting model was improved by manual building in Coot (Emsley et al., 2010) and was subsequently refined by BUSTER (Blanc et al., 2004). The final structure was validated using the MolProbity web server (Chen et al., 2010). For the bromoacetate-bound GLIC structure, anomalous maps were calculated in Coot. The refinement of the assigned bromoacetate molecules was however complicated by the fact that the bromoacetate occupancy is apparently lower than 1.0 owing to incomplete bromoacetate exchange and to possible radiation damage leading to bromine-carbon bond cleavage. As a result, we performed one round of refinement in which the bromine occupancy was allowed to vary. The mean occupancy of the five $\mathrm{Br}$ atoms was refined to a mean value close to 0.2 . A final round of refinement was then performed after fixing the occupancy of the $\mathrm{Br}$ atoms at 0.2. In the final model, most of the bromoacetate molecules fitted very well into the $2 F_{\mathrm{o}}-F_{\mathrm{c}}$ density map and the model was judged to be satisfactory after MolProbity validation.

\subsection{Poisson-Boltzmann calculations}

Both calculations used in Fig. 4(c) were performed using AquaSol (Koehl \& Delarue, 2010) as described in Sauguet, Poitevin et al. (2013).

\section{Results}

3.1. Structural evidence of acetate binding at an intersubunit site and an intrasubunit site in the GLIC ECD

The high-resolution structure $(2.4 \AA)$ of GLIC in the active state solved at low $\mathrm{pH}$ revealed the presence of two bound acetates per subunit originating from the crystallization buffer (Sauguet, Poitevin et al., 2013). One acetate molecule binds at an intersubunit site, the entrance to which lies on the external side of the receptor below loop C. Acetate is coordinated by the side chains of residues from the two adjacent monomers: Arg77 (from loop A) and Glu181 (from loop C) from one subunit and Arg105 (from loop E) from the neighbouring subunit (Fig. 2). This pocket is located just below the orthosteric site of pLGICs, which is atypical in GLIC owing to the absence of the 'aromatic box' formed by the aromatic residues from the $\mathrm{A}, \mathrm{B}$ and $\mathrm{C}$ loops involved in agonist binding. The second acetate molecule binds at an intrasubunit site between the inner and the outer $\beta$-sheets, the entrance to which is

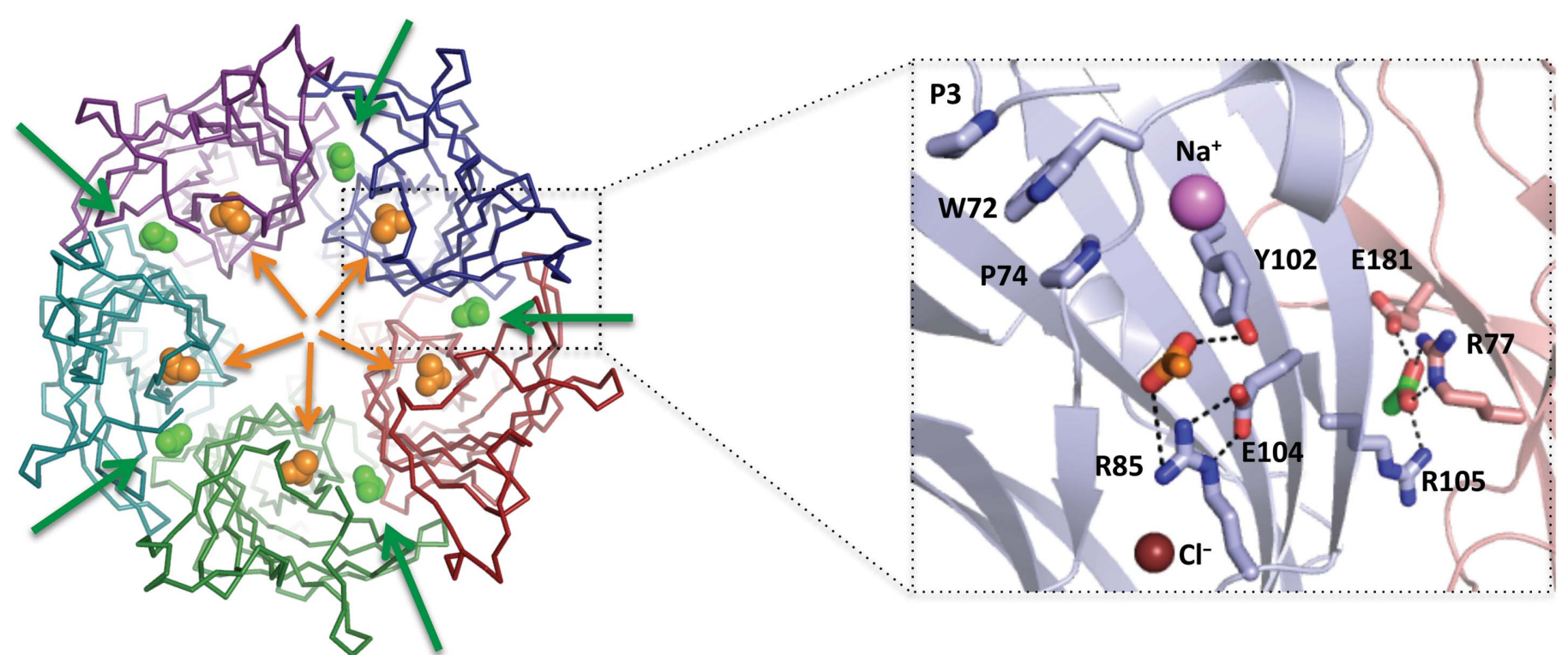

(a)

(b)

Figure 2

Detailed view of the two acetate-binding sites in the extracellular domain (ECD) of GLIC. (a) Top view of the receptor. Acetate molecules are shown as either green or orange spheres. Orange, intrasubunit acetate. Green, intersubunit acetate. Arrows show the entrance path to each site using the same colour scheme. (b) Molecular determinants of acetate (sticks) binding at the intrasubunit (orange) and the intersubunit (green) sites. Monovalent ions previously identified are shown as spheres (magenta for $\mathrm{Na}^{+}$, dark red for $\mathrm{Cl}^{-}$) 


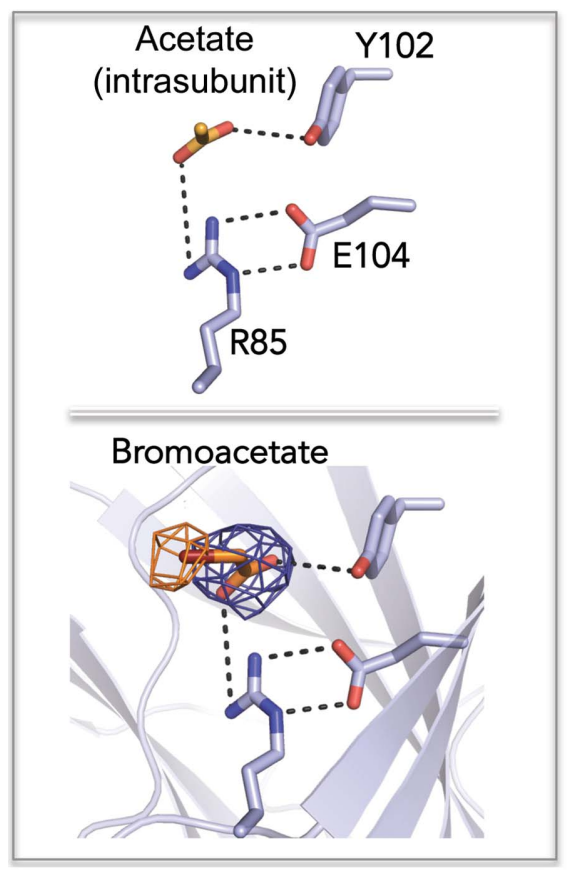

(a)

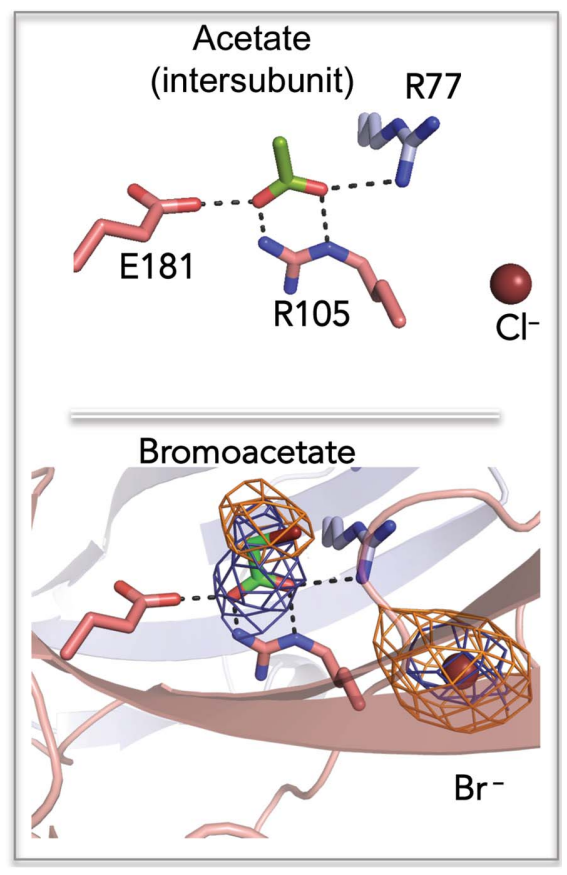

(b)

Figure 3

Evidence of two unique acetate-binding sites in the GLIC ECD as confirmed by the bromoacetatebound structure (PDB entry 4qh1). (a) Intrasubunit site. (b) Intersubunit site. Orange map: averaged anomalous density map of bromoacetate contoured at $3 \sigma$. Blue map, $2 F_{\mathrm{o}}-F_{\mathrm{c}}$ density map contoured at $1 \sigma$. Upper panel, acetate; lower panel, bromoacetate.

located in the vestibule. The acetate binds through a hydrogen bond to the side chain of Tyr102 and a salt bridge to the side chain of Arg 85, which is itself held in place by a salt bridge to Glu104 (Fig. 2). In order to further confirm acetate binding at these two sites in the ECD, we solved the GLIC structure in the presence of bromoacetate, an acetate analogue in which the methyl group is replaced by a bromomethyl moiety which produces a specific anomalous signal at the bromine absorption wavelength. The averaged anomalous map contoured at $3 \sigma$ revealed the presence of three (and only three) strong anomalous peaks. Two of the peaks correspond to the known intersubunit and intrasubunit acetate sites and also appear as positive peaks in the normal $F_{\mathrm{o}}-F_{\mathrm{c}}$ density map. This allowed us to unambiguously assign a bromoacetate molecule per site in the same orientation as the previously assigned acetates (Fig. 3). The third strong anomalous peak overlaps with the previously identified chloride ion, which has also been successfully replaced by a bromine ion upon crystallization in the presence of $\mathrm{NaBr}$ instead of $\mathrm{NaCl}$ (Sauguet, Poitevin et al., 2013). This suggests that the chloride ion was replaced by a bromide ion, presumably generated by spontaneous dissociation of the bromoacatete molecule, during the soaking experiment (Fig. 2). We conclude that the intersubunit and the intrasubunit ECD sites are the only acetate sites in GLIC.

\subsection{Acetate binding causes a local conformational change in} the extracellular domain of GLIC

In order to assess the effect of acetate binding on the structure, we solved the structure of GLIC in the absence of acetate. The acetate buffer was replaced by phosphate buffer, also at $\mathrm{pH} 4$. The overall $2.8 \AA$ resolution structure is highly similar to the acetate-bound structure, with an r.m.s.d. of $0.4 \AA$ over all $\mathrm{C}^{\alpha}$ atoms, but displays significant differences around the acetate-binding sites (Fig. 4). This structure is characterized by a marked displacement of the pre- $\beta 5$ loop, which results in changes in the orientation of several charged residues exposed to the lumen (Figs. $4 a$ and $4 b$ ). In particular, Asp86 and Asp88 undergo a reorientation in the phosphate structure (Fig. 4b). These Asp residues form a charged ring that captures cations entering the vestibule. Indeed, they were shown to bind either one divalent transition-metal ion $\left(\mathrm{Ni}^{2+}\right)$ or two monovalent cations $\left(\mathrm{Rb}^{+}\right)$in GLIC (Fig. 4b; Sauguet, Poitevin et al., 2013). This rearrangement is likely to impact the conductivity of the receptor, as the phosphate structure displays a lower cation density in the vestibule compared with the acetate structure (Fig. 4c). The reorganization observed in the phosphate structure also involves the acetate-binding sites, with Arg77 having a pivot role (Figs. $4 d, 4 e$ and $4 f$ ). While the intersubunit site is empty in the absence of acetate, the intrasubunit site is occupied by a chloride ion. Arg77, which is involved in the intersubunit acetate coordination, undergoes a major side-chain movement and a change of rotameric state that can be described as a $102^{\circ}$ change of the dihedral angle around the $\mathrm{C}^{\gamma}-\mathrm{C}^{\delta}$ bond, and now points towards this chloride ion. In addition, the Asp88 side chain forms an ion pair with the side chain of Arg77, stabilizing its new conformation.

\section{Discussion}

In this study, we characterize two acetate-binding sites in the GLIC ECD and describe its acetate-free open form by X-ray crystallography. This latter structure shows nontrivial conformational rearrangements in the ECD that should be considered. On the one hand, acetate binding occurs at well conserved pockets near the pLGIC orthosteric site that harbour allosteric modulators in some other pLGICs (Spurny et al., 2012; Miller et al., 2008). Thus, these sites are also likely to represent modulation sites in GLIC. This hypothesis is further reinforced by a recent study that revealed a new class of allosteric modulators targeting the extracellular domain of GLIC (Prevost et al., 2013). These molecules include cinnamic acid and caffeic acid derivatives that inhibit GLIC currents with micromolar affinity. Interestingly, their carboxylate group has been shown to be compulsory for the inhibitory effect, and their binding site was mapped by molecular docking and 
mutagenesis experiments to be in the vicinity of the pLGIC orthosteric site. In particular, for the Arg77Ala mutant the inhibition concentration shifts to higher concentrations by more than tenfold. This residue, which is involved in the coordination of the intersubunit acetate in GLIC (see Fig. 3), undergoes a significant side-chain rearrangement in our acetate-free structure. This may suggest that it is indeed important for GLIC modulation by acetate derivatives. In any case, further structural and functional studies will be needed in order to assess whether the described acetate-binding sites could indeed represent GLIC modulation sites.

The acetate-induced conformational rearrangement involves charged residues on the ECD. These rearrangements are particularly important to consider for GLIC which is activated by protons and no 'sizable' agonist targeting GLIC has been identified to date (Bocquet et al., 2007). At the molecular level, this may be owing to the absence of the characteristic 'aromatic box' located at the ECD at the interspace between subunits and which is involved in ligand binding in canonical pLGIC orthosteric sites (Nys et al., 2013). In GLIC, this 'aromatic box' is replaced by a patch of charged residues, among which Arg133 partially obstructs the putative ortho- steric pocket. To date, the proton-elicited activation mode of GLIC has not been completely elucidated. It is however safe to assume that at least one of the proton-binding sites is located in the ECD, as a chimera of GLIC ECD fused to the TMD of the human $\alpha 1$ glycine receptor ( $\alpha 1 \mathrm{GlyR}$ ) has also been shown to be activated by protons (Duret et al., 2011). As a result, any attempt to study the proton-elicited activation should take into account the conformation described here for the charged residues in the ECD.

The new acetate-free structure described here should be considered to be the unbiased active (open) structure of GLIC devoid of the conformational rearrangement owing to acetate binding. Although this structure displays only small conformational changes compared with the acetate-bound structure, the rearrangements observed upon acetate binding involve a key region where both $\mathrm{GluCl}$ and GABA-R place an insertion (Fig. 1). Actually $\mathrm{GluCl}$ has its aspartate D104 side chain exactly on the intrasubunit acetate binding site of GLIC. Thus, this rearrangement should be taken into account when performing calculations that require accurate structural information. For instance, molecular-dynamics simulations are usually performed based on GLIC structures in order to

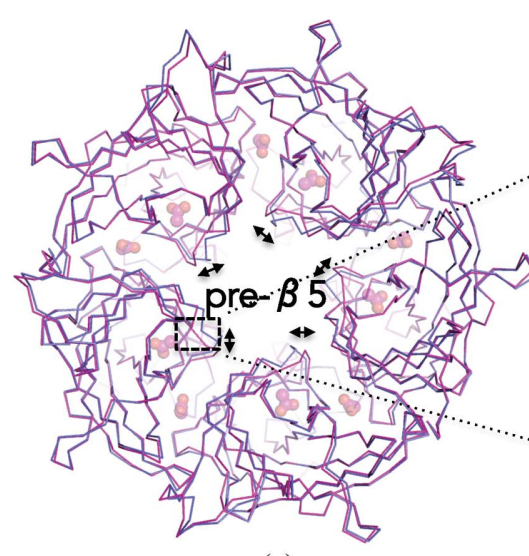

(a)

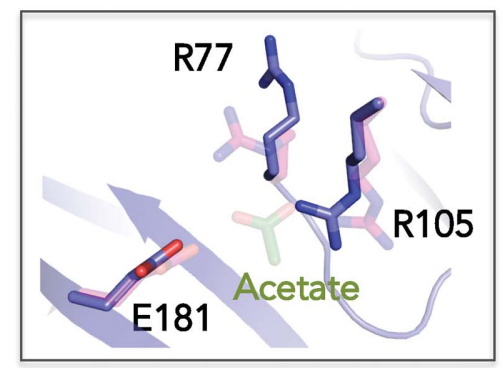

(d)

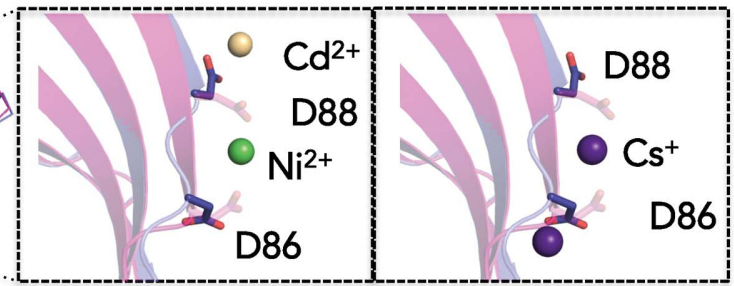

(b)

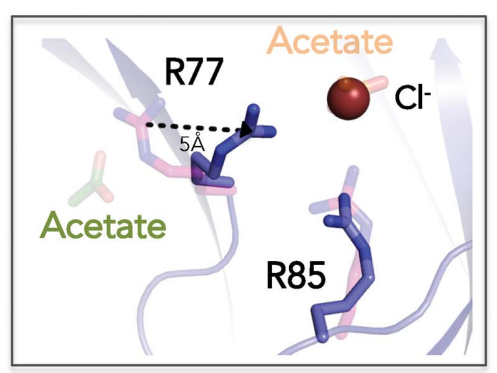

(e)
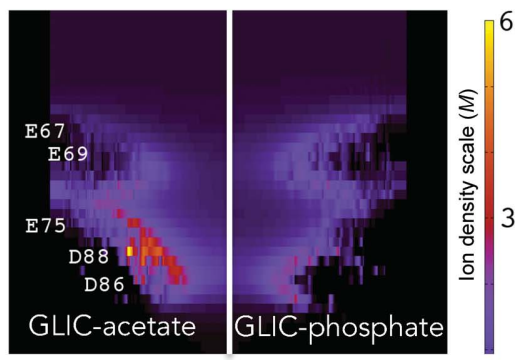

(c)

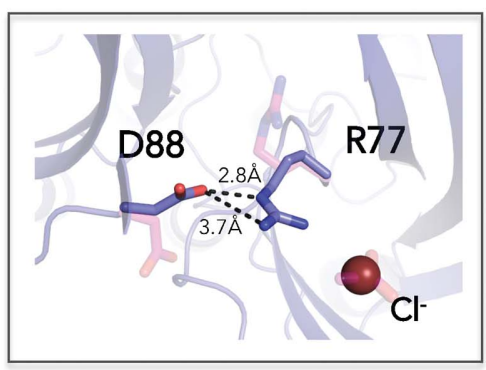

$(f)$

Figure 4

Comparison of the GLIC-acetate structure (PDB entry 4hfi, pink; Sauguet, Poitevin et al., 2013) with the GLIC-phosphate structure (PDB entry 4qh5, deep blue; this work) both at $\mathrm{pH}$ 4. $(a, b, c)$ Asp86-Asp88 movement. (a) Superimposition of the pentamers. Black arrows highlight the movements of the pre- $\beta 5$ loops. (b) Change of conformers of the pre- $\beta 5$ loop residues Asp86 and Asp88. Divalent or monovalent ions observed in different GLIC structures are also shown as coloured spheres [green sphere, $\mathrm{Ni}^{2+}$ ion (PDB entry 4npp; Sauguet, Shahsavar, Poitevin et al., 2014); golden sphere, Cd ${ }^{2+}$ ion (PDB entry 2xq7; Hilf et al., 2010); violet spheres, $\mathrm{Cs}^{+}$ions (PDB entry 4ila; Sauguet, Poitevin et al., 2013)]. (c) Cation density map in the vestibule in the two structures calculated by AquaSol (using an implementation available online at http://lorentz.dynstr.pasteur.fr; Koehl \& Delarue, 2010). (d, $e, f$ ) The pivot movement of the Arg77 side chain in the phosphate structure. (d) The Arg77 side chain points away from the empty intersubunit binding site. (e) The Arg77 side chain points to a chloride ion occupying the intrasubunit binding site; the black arrow highlights the $5 \AA$ translation of the Arg77 side chain between the acetate and the phosphate structures. $(f)$ Creation of an Arg77/Asp88 ion pair in the phosphate structure. The tip of the Arg77 side chain switches from the acetate intersubunit site to the acetate intrasubunit site and changes the conformation of Asp88. 
characterize the ion conduction, the gating mechanism and the allosteric transitions of Cys-loop family receptors (Calimet et al., 2013; Velisetty et al., 2014; Zhu \& Hummer, 2012). Such simulations should now be performed using the GLIC acetatefree structure described in this study as the real open form of the receptor.

\section{Acknowledgements}

We thank Frederic Poitevin and Pierre-Jean Corringer for helpful suggestions and careful reading of the manuscript. We are indebted to Synchrotron SOLEIL (Saint Aubin) and the ESRF (Grenoble) for excellent beamline facilities. We acknowledge the financial support from ANR grant 'Pentagate' (ZF) and Bourse Roux (LS).

\section{References}

Blanc, E., Roversi, P., Vonrhein, C., Flensburg, C., Lea, S. M. \& Bricogne, G. (2004). Acta Cryst. D60, 2210-2221.

Bloomenthal, A. B., Goldwater, E., Pritchett, D. B. \& Harrison, N. L. (1994). Mol. Pharmacol. 46, 1156-1159.

Bocquet, N., Nury, H., Baaden, M., Le Poupon, C., Changeux, J.-P., Delarue, M. \& Corringer, P.-J. (2009). Nature (London), 457, 111-114.

Bocquet, N., Prado de Carvalho, L., Cartaud, J., Neyton, J., Le Poupon, C., Taly, A., Grutter, T., Changeux, J.-P. \& Corringer, P.-J. (2007). Nature (London), 445, 116-119.

Calimet, N., Simoes, M., Changeux, J.-P., Karplus, M., Taly, A. \& Cecchini, M. (2013). Proc. Natl Acad. Sci. USA, 110, E3987-E3996.

Chen, V. B., Arendall, W. B., Headd, J. J., Keedy, D. A., Immormino, R. M., Kapral, G. J., Murray, L. W., Richardson, J. S. \& Richardson, D. C. (2010). Acta Cryst. D66, 12-21.

Corringer, P.-J., Poitevin, F., Prevost, M. S., Sauguet, L., Delarue, M. \& Changeux, J.-P. (2012). Structure, 20, 941-956.

Duret, G., Van Renterghem, C., Weng, Y., Prevost, M., Moraga-Cid, G., Huon, C., Sonner, J. M. \& Corringer, P.-J. (2011). Proc. Natl Acad. Sci. USA, 108, 12143-12148.

Emsley, P., Lohkamp, B., Scott, W. G. \& Cowtan, K. (2010). Acta Cryst. D66, 486-501.

Hassaine, G., Deluz, C., Grasso, L., Wyss, R., Tol, M. B., Hovius, R., Graff, A., Stahlberg, H., Tomizaki, T., Desmyter, A., Moreau, C., Li, X.-D., Poitevin, F., Vogel, H. \& Nury, H. (2014). Nature (London), 512, 276-281.

Hilf, R. J. C., Bertozzi, C., Zimmermann, I., Reiter, A., Trauner, D. \& Dutzler, R. (2010). Nature Struct. Mol. Biol. 17, 1330-1336.
Kabsch, W. (2010). Acta Cryst. D66, 125-132.

Koehl, P. \& Delarue, M. (2010). J. Chem. Phys. 132, 064101.

Laube, B. (2002). Eur. J. Neurosci. 16, 1025-1036.

Miller, P. S. \& Aricescu, A. R. (2014). Nature (London), 512, 270-275.

Miller, P. S. \& Smart, T. G. (2010). Trends Pharmacol. Sci. 31, 161-174.

Miller, P. S., Topf, M. \& Smart, T. G. (2008). Nature Struct. Mol. Biol. 15, 1084-1093.

Murshudov, G. N., Skubák, P., Lebedev, A. A., Pannu, N. S., Steiner, R. A., Nicholls, R. A., Winn, M. D., Long, F. \& Vagin, A. A. (2011). Acta Cryst. D67, 355-367.

Nury, H., Bocquet, N., Le Poupon, C., Raynal, B., Haouz, A., Corringer, P.-J. \& Delarue, M. (2010). J. Mol. Biol. 395, 1114-1127.

Nury, H., Van Renterghem, C., Weng, Y., Tran, A., Baaden, M., Dufresne, V., Changeux, J.-P., Sonner, J. M., Delarue, M. \& Corringer, P.-J. (2011). Nature (London), 469, 428-431.

Nys, M., Kesters, D. \& Ulens, C. (2013). Biochem. Pharmacol. 86, 1042-1053.

Pan, J., Chen, Q., Willenbring, D., Yoshida, K., Tillman, T., Kashlan, O. B., Cohen, A., Kong, X.-P., Xu, Y. \& Tang, P. (2012). Nature Commun. 3, 714.

Prevost, M. S., Delarue-Cochin, S., Marteaux, J., Colas, C., Van Renterghem, C., Blondel, A., Malliavin, T., Corringer, P.-J. \& Joseph, D. (2013). J. Med. Chem. 56, 4619-4630.

Prevost, M. S., Sauguet, L., Nury, H., Van Renterghem, C., Huon, C., Poitevin, F., Baaden, M., Delarue, M. \& Corringer, P.-J. (2012). Nature Struct. Mol. Biol. 19, 642-649.

Sauguet, L., Howard, R. J., Malherbe, L., Lee, U. S., Corringer, P.-J., Harris, R. A. \& Delarue, M. (2013). Nature Commun. 4, 1697.

Sauguet, L., Poitevin, F., Murail, S., Van Renterghem, C., Moraga-Cid, G., Malherbe, L., Thompson, A. W., Koehl, P., Corringer, P.-J., Baaden, M. \& Delarue, M. (2013). EMBO J. 32, 728-741.

Sauguet, L., Shahsavar, A. \& Delarue, M. (2014). Biochim. Biophys. Acta, 1850, 511-523.

Sauguet, L., Shahsavar, A., Poitevin, F., Huon, C., Menny, A., Nemecz, À., Haouz, A., Changeux, J.-P., Corringer, P.-J. \& Delarue, M. (2014). Proc. Natl Acad. Sci. USA, 111, 966-971.

Spurny, R., Billen, B., Howard, R. J., Brams, M., Debaveye, S., Price, K. L., Weston, D. A., Strelkov, S. V., Tytgat, J., Bertrand, S., Bertrand, D., Lummis, S. C. R. \& Ulens, C. (2013). J. Biol. Chem. 288, 8355-8364.

Spurny, R. et al. (2012). Proc. Natl Acad. Sci. USA, 109, e3028-E3034.

Velisetty, P., Chalamalasetti, S. V. \& Chakrapani, S. (2014). J. Biol. Chem. 289, 3013-3025.

Walters, R. J., Hadley, S. H., Morris, K. D. \& Amin, J. (2000). Nature Neurosci. 3, 1274-1281.

Winn, M. D. et al. (2011). Acta Cryst. D67, 235-242.

Zhu, F. \& Hummer, G. (2012). J. Chem. Theory Comput. 8, 37593768 . 